\title{
2.2
}

\section{Monitoring Methods Based on Fish}

\section{Michele Scardi, Lorenzo Tancioni and Stefano Cataudella}

\author{
2.2.1 Introduction \\ 2.2.2 Multimetric Indices \\ 2.2.3 Index of Biotic Integrity \\ 2.2.4 Other Biotic Indices \\ 2.2.5 Comparison with Reference Conditions \\ 2.2.6 Modeling Fish Assemblages \\ 2.2.7 Conclusions and Perspectives \\ References
}

\subsubsection{INTRODUCTION}

Fish have been used as biological indicators of environmental quality in many different aquatic ecosystems (Fausch et al., 1990; Whitfield, 1996) and their role as indicators has been explicitly mentioned in the legislation about water resources and aquatic environments, not only in the European Union and USA, but also in other countries (European Commission, 1992; European Union, 2000; Kurtz et al., 2001). In all cases, these legislations focus on the need for an improvement in environmental quality, as well as for the assessment of ecological integrity as key tools for conservation, restoration and management activities.

During the last twenty years, biological monitoring has gained a broader consensus with respect to chemical monitoring, because the latter often misses relevant

Biological Monitoring of Rivers Edited by G. Ziglio, M. Siligardi and G. Flaim (C) 2006 John Wiley \& Sons, Ltd. 
anthropogenic perturbations (e.g. channelization of river stretches) that may induce severe habitat degradation with little or no impact on water quality. Moreover, biotic responses usually integrate over time and space the effect of such perturbations, thus reducing the sampling error, which is usually smaller for biological attributes than for chemical ones. In fact, physical and chemical attributes of water are unsuccessful as surrogates for measuring biotic integrity (Karr and Dudley, 1981). This opinion is also supported by Oberdorff and Hughes (1992), who used data about the fish assemblage in the Seine River catchment to assess water quality. They found that comparisons between a biotic index and an independent water quality index (based on water chemistry) indicated that the former was a more sensitive and robust measure of water quality.

The usage of fish species as indicators in aquatic ecosystems is based on the assumption that fish species and fish assemblages are sensitive indicators, which are able to detect subtle environmental changes (Karr, 1981; Shamsudin, 1988). Obviously, there are both advantages and disadvantages in using fish fauna as a biotic indicator, which depend on its particular ecological characteristics and on the scale of its interactions with the environment.

The advantages of biotic indicators of water quality based on fish fauna are numerous. For instance, fish assemblages are present in all aquatic ecosystems and their structure not only depends on biotic, physical and chemical constraints, but also on the hydromorphological continuity of rivers and streams.

Most fish species are easy to identify and specimens can be sampled and then immediately released after identification and biometric measurements, while the biology of fish species is usually well know, in many cases even at the physiological level.

From an ecological point of view, fish assemblages often include species that belong to different trophic levels, as well as to different trophic guilds. Changes in the structure of fish populations and assemblages integrate responses to environmental disturbances over long time intervals, while, depending on the characteristics of each species, they integrate those responses over different spatial scales: sedentary species respond to local disturbances, whereas mobile species respond to diffuse stressors. Moreover, a useful characteristic of fish as indicators is that many species are well suited for ecotoxicological tests, as they can be easily kept in captivity. Finally, there is a broad public awareness of the iconic role of fish fauna in aquatic ecosystems and this awareness, in conjunction with the economic value of many species, makes it easier to enforce monitoring activity based on fish or to take into account fish fauna in economic analyses.

Obviously, there are also disadvantages in the usage of fish as biotic indicators of environmental quality. In fact, unbiased sampling may be difficult or impossible to attain in some cases (e.g. large rivers). Fishing gear may be more or less selective, depending on environmental characteristics, as well as on fish species and size, while sampling may be biased by the mobility of fish according to seasonal, daily, nictemeral or occasional patterns. As for their ecological response to perturbations, some fish species may tolerate pollutants that are dangerous to other biota and they can also actively avoid anthropogenic disturbance. The advantages in the usage of fish 
Table 2.2.1 Effects of disturbances on fish fauna at different levels of biotic organization

\begin{tabular}{|c|c|c|}
\hline Level & Undisturbed fish fauna & Disturbed fish fauna \\
\hline Cells & $\begin{array}{l}\text { Normal cell functionality, stable } \\
\text { lysosomes, genetic integrity }\end{array}$ & $\begin{array}{l}\text { Ongoing detoxifying activity, genetic } \\
\text { damages }\end{array}$ \\
\hline Individuals & $\begin{array}{l}\text { No morphological anomalies, low } \\
\text { parasitism, normal behaviour, } \\
\text { normal condition factor }\end{array}$ & $\begin{array}{l}\text { Fin damages and other lesions or } \\
\text { anomalies, tumours, abnormal } \\
\text { behaviour, impaired condition } \\
\text { factor }\end{array}$ \\
\hline Populations & $\begin{array}{l}\text { Self-sustaining populations, adequate } \\
\text { larval recruitment, normal } \\
\text { demographic structure, all the age } \\
\text { classes are present, predictable } \\
\text { spatial distribution }\end{array}$ & $\begin{array}{l}\text { Insufficient or null larval recruitment, } \\
\text { low number of juveniles and } \\
\text { sub-adults, altered spatial } \\
\text { distribution }\end{array}$ \\
\hline Assemblages & $\begin{array}{l}\text { Normal to high diversity, many guilds } \\
\text { are present, complex biotic } \\
\text { interactions, expected seasonal } \\
\text { cycles }\end{array}$ & $\begin{array}{l}\text { Low diversity, some guilds are not } \\
\text { present, loss of sensitive species, } \\
\text { reduced biotic interactions, altered } \\
\text { seasonal cycles }\end{array}$ \\
\hline
\end{tabular}

as indicators, however, outweigh the disadvantages, especially in the case where environmental quality is not to be assessed on a very small spatial scale. The expected effects of disturbances on fish fauna are summarized in Table 2.2.1, with respect to different levels of biotic organization.

Independently of the level of biological organization, as well as of the spatial and temporal scale, the evaluation of the ecological status of an aquatic ecosystem based on biotic indicators (fish, as well as other organisms) is only possible if a suitable metric (or a set of metrics) is defined, which is appropriate for measuring deviation of the observed conditions from their expected status.

This goal can be achieved in different ways, but two main options are available: (1) measuring the deviation of a set of functional and structural features of fish assemblages from those that are expected for pristine fish assemblages; (2) measuring the distance or similarity between observed fish assemblages and properly selected reference fish assemblages. In the latter case, the reference can be obtained from a number of sources, such as previous observations, historical records, biogeographical inferences, mathematical models, empirical knowledge, etc.

In both the above-mentioned cases, the whole fish assemblage is usually taken into account. This does not imply that single species cannot be used as indicators. On the contrary, single species can be used as biomonitoring tools, for instance, in ecotoxicological tests or by screening DELT (i.e. deformities, eroded fins, lesions, and tumours) anomalies. In fact, at the lowest end of the biotic organization scale, the effects of ecological disturbances on fish fauna can be detected by analysing specific molecular, genetic, metabolic or morphological responses, i.e. by taking into account appropriate biomarkers.

Although the use of biomarkers is gaining momentum (for a thorough review, see van der Oost et al., 2003), it should only be considered in fish-based monitoring 
in case it is really needed and supported by a specific ecological rationale (e.g. in order to trace the bioaccumulation or biomagnification of pollutants that are not as concentrated in abiotic matrices as to directly affect community structure and functioning). Most fish species belong to the upper trophic levels and therefore they are often involved into such processes. Moreover, fish are complex and sensitive organisms that are well suited for setting up laboratory experiments, but they can also be sampled in a non-destructive way (e.g. by collecting blood samples).

As a matter of fact, the occurrence of a fish species is always a direct evidence for ecological conditions that are at least compatible with its survival, although it does not imply the existence of a self-sustaining, healthy population. On the other hand, the interpretation of biomarkers that are not directly related to short-term physiological responses is not as straightforward because of the mobility of most fish species. Moreover, biomarker-based approaches are typically species-specific and therefore difficult to generalize. Therefore, in this chapter biomarkers and fish physiological responses will be only taken into account as attributes of the fish assemblage in assemblage-oriented evaluation procedures, which, in contrast, will be discussed in detail.

\subsubsection{MULTIMETRIC INDICES}

Most of the monitoring methods based on fish fauna rely upon biotic indices and, in particular, upon multimetric indices, which combine different indicators (i.e. metrics) into a single score. Each candidate metric is separately tested and calibrated in order to adequately scale its values to obtain a unitless score, which can be easily aggregated to other scores into a multimetric index.

Different approaches have been used to arrange and to analyse biotic data, but they all start out with a list of the organisms that were collected and identified. In the past, the distribution of a few indicator species was used to assess watershed health, but the assessment procedure was often a little more complicated than just recording the occurrence of these indicator species. More recently, other sources of ecological information, such as population structure, presence of anomalies or diseases, etc., have been also taken into account and combined into multimetric indices.

Such multimetric indices were first called biotic indices because they scored the pollution tolerance of many different species, which were regarded as biological indicators. While biotic indices were expanding in use, other indices, such as those based on species diversity, grew in popularity and were used for many years. Recently, multimetric indices, such as the Index of Biotic Integrity (Karr, 1981), have become a standard.

Four main points should be taken into account in developing an effective multimetric biotic index:

(1) Classifying homogeneous biotopes within or across ecoregions (e.g., large or small streams; high- or low-gradient streams, etc.). 
(2) Selecting those metrics that reflect the most relevant and reliable responses to the effects of disturbances.

(3) Defining sampling designs and protocols that allow us to accurately measure the selected metrics in the field.

(4) Analysing collected data to relate this information to the watershed health as straightforwardly as possible (e.g. by means of simple linear functions).

Obviously, even the best index, if not adequately tested and widely accepted, is practically useless. Therefore, it is of paramount importance to rely on the widest base of testers and collaborators when developing a multimetric index.

Even when a multimetric index has been correctly developed (see, for instance, Hughes et al., 1998), its ability to measure environmental perturbations depends on the right combination of metrics that are taken into account. Of course, there are no general rules that can help in selecting proper metrics, but usually the latter are chosen on the basis of their presumed general ecological relevance or because of their responsiveness to specific perturbations (e.g. as shown by ecotoxicological tests). In any case, the selection of a metric should be also supported by adequate statistical evidences, and only metrics that are linearly or monotonically related to specific stressors or to general environmental conditions should be taken into account. The selection of metrics, however, is often based on literature references, on expert judgement (especially when existing indices are adapted to different regional conditions) or on a priori belief. A typical example of potentially biased metrics is the species richness, which is considered as a key metric in most multimetric indices. The intermediate disturbance hypothesis (Connell, 1978) and many field evidences, in fact, suggest that species richness is not monotonically related to environmental quality, as the highest values are usually observed in moderately perturbed sites rather than in pristine ones. Thus, the overall efficiency of a multimetric index can be impaired by a poor or biased selection of the underlying metrics.

\subsubsection{INDEX OF BIOTIC INTEGRITY}

The Index of Biotic Integrity (IBI) gained considerable popularity as a multimetric method for the assessment of the integrity of fish assemblage during the last two decades, not only in the USA (Karr and Dudley, 1981; Karr et al., 1986; Plafkin et al., 1989; Fausch et al., 1990), but also in other countries (Hughes and Oberdorff, 1999). The original version of the IBI includes twelve assemblage attributes (see Table 2.2.2) that are compared to values expected for an unperturbed stream of the same size in the same ecoregion (Plafkin et al., 1989). The assemblage attributes can be grouped into three main categories, i.e. species richness and assemblage composition, trophic composition and fish abundance and condition.

These attributes are scored according to the uneven integers 1, 3, and 5, which stand, respectively, for conditions that deviate strongly, moderately or slightly from 
Table 2.2.2 Metrics of the Index of Biotic Integrity as originally developed (adapted from Karr, J. R., Fausch, F. D., Angermeir, P. L., Yant, P. R. and Schlosser, I. J., 1986, Assessing Biological Integrity in Running Waters: A Method and its Rationale, Special Publication 5, Illinois Natural History Survey, Chicago, IL, USA)

\begin{tabular}{|c|c|}
\hline Category & Metric \\
\hline \multirow{6}{*}{$\begin{array}{l}\text { Species richness and } \\
\text { assemblage composition }\end{array}$} & 1. Total number of fish species \\
\hline & 2. Number and identity of darter species \\
\hline & 3. Number and identity of sunfish species \\
\hline & 4. Number and identity of sucker species \\
\hline & 5. Number and identity of intolerant species \\
\hline & $\begin{array}{l}\text { 6. Proportion of individuals as green sunfish (tolerant } \\
\text { species) }\end{array}$ \\
\hline \multirow[t]{3}{*}{ Trophic composition } & 7. Proportion of individuals as omnivores \\
\hline & $\begin{array}{l}\text { 8. Proportion of individuals as insectivorous cyprinids } \\
\text { (minnows) }\end{array}$ \\
\hline & 9. Proportion of individuals as top carnivores \\
\hline \multirow{3}{*}{$\begin{array}{l}\text { Fish abundance and } \\
\text { condition }\end{array}$} & 10. Number of individuals in sample \\
\hline & 11. Proportion of individuals as hybrids \\
\hline & $\begin{array}{l}\text { 12. Proportion of individuals with disease, tumours, fin } \\
\text { damage or skeletal anomalies }\end{array}$ \\
\hline
\end{tabular}

situations at reference sites (Fausch et al., 1990). The overall score, obtained by summing up those of the twelve assemblage attributes, is then categorized into discrete classes according to expert judgment, in order to provide an integrated scoring system for ecological integrity. A description of the compositional attributes of the fish assemblage is usually provided for each quality class. Usually, IBI scores are presented directly, or may be expressed as a percentage of the maximum (Lyons et al., 1995).

The original version of the IBI has been modified more or less substantially in order to preserve its rationale independently of the ecoregion in which it is applied. Therefore, it is probably more correct to think about the IBI as a flexible conceptual framework that can be easily adapted on a regional scale.

Simon and Lyons (1995) pointed out that the IBI is not an index based on community analysis, but rather a procedure involving several hierarchical biotic levels and based on a sample of the assemblage. Since its first application, the IBI has been criticized by some Authors (e.g. by Suter, 1993), although strong counter arguments have been also presented by others (e.g. Simon and Lyons, 1995; Karr and Chu, 1997; Hughes et al., 1998).

Although the ecological principles on which the IBI is based are sound, its application in the original form, as well as in other adapted versions, may present problems when considered for use in some ecological regions.

In fact, the IBI relies on biotic attributes that require detailed historical and ecological information which is often not available. A particular problem is to be tackled when dealing with attributes involving proportions of fish species or functional 
groups, as little reference (e.g. pre-impact) information on them is usually available. Moreover, available data are often biased from a quantitative point of view. Lyons et al. (1995), for instance, developed a preliminary IBI for streams in west central Mexico but expressed concerns on the scarcity of fish community data.

Another potential drawback of the IBI is its lack of sensitivity with respect to some disturbances. For instance, in the USA it was found that the IBI did not indicate a degradation of biotic integrity in prairie streams following intensive testing of armored vehicles. Fishes were naturally adapted to droughts and flash floods and their presence, as well as the structure of the assemblage, depended on their rate of colonization rather than on habitat changes (Bramblett and Fausch, 1991). A similar situation can be expected in other ecoregions in which high variability in environmental conditions is observed, especially when associated with variability and unpredictability of rainfall and runoff within seasons and between years. In other words, a naturally high disturbance regime to which fish are adapted may affect the ability of the IBI to evaluate ecological quality, especially because there are several anthropogenic changes that may actually mimic these natural disturbance regimes.

A major problem in the adaptation of the IBI to European and other ecoregions is the number of fish species, which may be significantly less than in North American rivers. This problem affects all of the European ecoregions, but it is much more evident in Southern European rivers and streams, where only a handful of species is found. In such situations, it is not possible to adapt the original IBI scheme and deeper changes are needed in order to optimally exploit the relevant information conveyed by a simplified fish assemblage structure. The presence of juveniles, or even the age structure of fish populations, for instance, can be assumed as an example of an alternate metric in species-poor situations.

Notwithstanding these problems, the original IBI has been successfully adapted to many ecoregions. Several examples of localized IBIs exist not only for the United States and European countries (see for instance, Oberdorff and Hughes, 1992), but also in many other countries, like, for instance, Canada, Mexico, Australia, South Africa, Guinea, Namibia, Cameroon, Korea, etc. (see, respectively, Steedman, 1988; Lyons et al., 1995; Kleynhans, 1999; Harris, 1995; Hugueny et al., 1996; Hay et al., 1996; Kamdem Toham and Teugels, 1999; An et al., 2002).

\subsubsection{OTHER BIOTIC INDICES}

IBIs are not the only methods for evaluating environmental quality on the basis of fish assemblages. In fact, several other approaches have been proposed, and some of them rely upon different rationales. However, it is very difficult to trace the exact boundary between IBI-inspired methods and other procedures, because the underlying ecological concepts are obviously related.

MuLFA, for instance, is a method proposed by Schmutz et al. (2000) for the Austrian rivers and streams, which is certainly different from IBI. In fact, it takes 
into account multiple level of organization of fish fauna and river-type-specific assessment criteria, namely, presence of river-type-specific species, presence of selfsustaining populations, shifts in fish region, number of missing guilds, alterations in guild composition, changes in biomass and density, and changes in population age structure.

The final assessment of ecological integrity is obtained as a weighted average of the scores assigned to each criterion. An advantage of the MuLFA approach relative to other biotic indices is that the weighting scheme is not the same for all of the river types, thus allowing us to optimize the assessment of ecological integrity on a functional and regional basis. Another advantage of this simple and flexible method is that it encompasses different temporal and spatial scales, thus allowing the detection of a wide range of environmental effects of human alterations.

Other biotic indices are more closely related to the original IBI, although they focus on more sophisticated - and, probably, objective - methods for selecting or weighting an optimal set of metrics. An example of such an index is the one proposed for the Walloon part of the Meuse river basin (Belgium) by Kestemont et al. (2000). This index was originally developed on the basis of twelve metrics by adapting the IBI rationale to the local ecological conditions. Then, a multivariate statistical procedure based on Principal Component Analysis (PCA) was used to identify the most relevant metrics with respect to local disturbances. In particular, a subset of metrics was selected on the basis of their PCA factor loadings, thus allowing the downscaling of the index to a simplified version which preserved most of the efficiency of the original version in assessing the ecological integrity of local rivers and streams.

Several indices include metrics based on population structure data, but the most straightforward implementation of this concept is probably the one that Badino et al. (1992) proposed for Italian rivers. Their Ichthyologic Index (II) is computed by multiplying species richness by a linear combination of two factors, obtained from tables provided by the authors, which accounts for population structure (presence of juveniles, sub-adults and adults) and for abundance of fish fauna relative to species richness. In this way, the II takes into account the two main components of fish assemblage diversity, namely the species richness to fish abundance ratio and the average demographic complexity of local fish populations. The II score can be also discretized in order to express the estimate of ecological integrity according to a scale of five quality classes.

\subsubsection{COMPARISON WITH REFERENCE CONDITIONS}

Most problems with the application of IBI and related indices arise in situations in which the fish assemblage structure is too simple and therefore it cannot convey enough information about the biotic response to environmental perturbations. Moreover, the growing number of different implementation of IBI-inspired multimetric 
indices, although necessary for a better adaptation to ecoregional conditions, is certainly narrowing the number of users of each local index, which often cannot be validated on the basis of a large number of independent applications.

Therefore, measuring distance or similarity between the observed fish assemblage and a reference one seems a more objective approach to the assessment of ecological integrity than computing biotic indices. Of course, biotic indices may provide useful insights into ecosystem quality and they are certainly adequate in a number of practical applications, but they are always based on metrics that are selected on a subjective basis. It is obvious that a biotic index can be unreliable if wrong or scarcely relevant metrics are used, but it is still inherently subjective even when ecologically sound and sensitive metrics are carefully selected. For instance, in many cases closely related metrics are simultaneously used in the same index, thus increasing the relative influence of a single underlying ecological criterion. The most obvious example of such a lack of independence between metrics is provided by the number of species and the number of individuals in a given sample, which are both very common in biotic indices. Even though in low diversity assemblages it is possible to observe many individuals belonging to a very limited number of species, it is not possible to record many species in case only a few individuals have been observed. Moreover, in ecologically homogeneous sites the assemblage diversity is not likely to vary too much, and the number of species and number of individuals are more closely dependent on each other (and both of them depend on the sampling techniques). Thus, taking simultaneously into account both of these metrics increases the actual weight of species richness in the multimetric score.

Comparing observed and reference species richness is the simplest way to evaluate environmental quality using fish assemblages. This method has been applied in many cases and the observed to expected number of species ratio $(\mathrm{O} / \mathrm{E})$ has been regarded as an ecological indicator. According to this approach, the ratio should be larger than one in unperturbed conditions and smaller than one in perturbed conditions. The rationale supporting this method is absolutely straightforward and it has been applied in many different cases, such as, for instance, in the RIVPACS approach based on benthic macroinvertebrates (Wright et al., 1989). However, it can be misleading. In fact, it is certainly true that strong disturbances induce a decrease in species richness because of the exclusion of non-tolerant species, but it is also true that moderate perturbations may actually favour an increase in species richness. As already mentioned about the selection of metrics in multimetric indices, the intermediate disturbance hypothesis (Connell, 1978) provides a theoretical background for this empirical evidence. Therefore, species richness should not be regarded as a criterion for evaluating environmental quality because in many cases it is not monotonically related to disturbance.

A problem with multimetric indices that is sometimes overlooked is that the latter cannot be readily applied in the case of "information-poor" situations, such as those often found in Africa or in other developing countries. Therefore, alternate solutions should be considered instead, such as those based on community analysis, in order 
to assess ecological quality by comparing fish assemblage composition in a set of different sites. An application of this approach was presented by Ramm (1988), who developed a community degradation index (CDI) based on the principles of the Jaccard similarity index (Jaccard, 1900, 1901, 1908), which involves the number of species that are found both in the site to be evaluated and in a reference site, excluding other ecological aspects (i.e. trophic specialization, habitat specialization and intolerance) and considering abundance information unreliable.

Methods based on the comparison of the observed fish assemblage to reference conditions are not affected by problems related to the selection of a suitable set of metrics. However, a critical step (and not a minor one) is the selection of an appropriate measure for distance or similarity between observed and reference assemblages. In fact, this measure must be accurately selected according to the quality and to the nature of the available information, which may be more or less affected by errors. For instance, information may be inaccurate from the quantitative point of view, or it may be not completely reliable as far as absence of species (that is usually an implicit assumption if no specimens are collected) is concerned. In particular, when species-absence data are reliable, they contribute to the overall information about the structure of a fish assemblage, whereas in many cases information about absence is not completely dependable, and species that are reported as absent may be actually present. In the first case, the meaning of absence and presence data is opposite, but equivalent, and symmetrical similarity coefficient can be used (e.g. simple matching coefficient). On the contrary, in the second case only the meaning of species presence is unequivocal, and absence records should be ignored. In this case, asymmetrical similarity coefficients are more appropriate (e.g. Jaccard's similarity).

In case quantitative differences are relevant, Euclidean distance or 'city-block' (Manhattan) metrics are usually adequate, whereas other distance coefficients are more appropriate in the case where relative abundances are to be compared. The complement of the Whittaker's association index (Whittaker, 1952) is a suitable choice for comparing abundance data normalized relative to sample total abundance, and it is particularly effective if the species lists to be compared are quantitatively heterogeneous. Finally, in case the role species play is independent of their abundance, the Canberra metric (Lance and Williams, 1966) assigns to each species the same weight. The Bray-Curtis distance (Bray and Curtis, 1957), which is frequently used in community studies, varies within the $[0,1]$ interval, thus allowing us to compare different distance values very easily. Providing further details on similarity and distance coefficients is beyond the scope of this present chapter, but a complete presentation, including many other coefficients, as well as relevant information about their usage, can be found in Legendre and Legendre (1998).

In order to measure the distance from the reference conditions, the ecological meaning of "reference", as well as the associated fish assemblages, have to be clearly defined. The most obvious solution is to select a set of pristine sites and to assume their fish assemblages as the reference, thus considering as disturbed those sites in which, given environmental conditions similar to those of a reference site, the fish assemblage is different. 
However, sampling fish assemblages at pristine sites is not the only way to define reference conditions, and in many cases it is not even possible because of the lack of really pristine sites. In such cases, reference conditions may be defined on the basis of other sources of information, such as historical records or species-distribution models.

\subsubsection{MODELING FISH ASSEMBLAGES}

While defining reference conditions according to historical records is a straightforward approach and data availability is the only real constraint, modeling species distribution involves a more complex procedure.

In fact, when information about species composition of fish assemblages is not available, neither from past studies nor from other records, the only viable solution for obtaining information about reference assemblages is based on mathematical models, which can predict the presence (or the abundance) of fish species, given an adequate amount of ecological information. In particular, the physical structure of rivers and streams can be often described by a relatively small number of morphodynamic attributes that, in turn, directly affect the distribution of fish species or which are related to other relevant attributes that are more difficult to quantify (e.g. discharge).

The best suited mathematical models for this task are based on an empirical approach, i.e. on the direct extraction of information from existing data sets. Statistical models, like those based on multiple linear or logistic regression, are a typical example of this category of models. An example of this approach was presented by Oberdorff et al. (2001), who developed a set of probabilistic models based on logistic regression that are aimed at predicting the occurrence of 34 fish species in French rivers and streams. The models were based on eight predictive variables (including gradient, elevation, July and January mean daily maximum air temperature, stream width, mean depth and distance from headwater sources) and on the average explained about $60 \%$ of the total variation in species richness. This result, according to the authors, was comparable to those of more sophisticated techniques, like, for instance, Artificial Neural Networks (ANNs), and the models were then applied for defining a fish-based index aimed at a nation-wide application in French rivers.

However, a clear trend in the literature about species distribution modeling shows that empirical models based on ANNs have become more and more popular during the last decade, proving to be the best tools for these applications. In fact, although several different modeling techniques may provide similar results in terms of overall accuracy, ANNs produced the greatest number of statistically significant models as far as fish fauna composition is concerned (Olden and Jackson, 2002).

Even though the idea of modeling fish fauna composition on the basis of environmental variables is not new (e.g. Faush et al., 1988), only recently have ANNs been applied to this problem. ANNs have been used to predict fish species richness (e.g. Guegan et al., 1998), as well as density and biomass of single fish populations (Baran et al., 1996; Lek et al., 1996a,b; Mastrorillo et al., 1997a,b) and ecological 
characteristics of fish assemblages (Aguilar Ibarra et al., 2003). As far as fish assemblages composition at river basin scale is considered, only a few models have been developed so far (e.g. Boët and Fhus, 2000; Olden and Jackson, 2001; Joy and Death, 2005; Scardi et al., 2004, 2005). A complete description of the way ANNs work is obviously beyond the scope of this chapter and readers who are interested in the technical details will find more information and an introduction to ecological applications of ANNs in Lek and Guégan (1999) or in Fielding (1999).

An example of the potentialities of ANN models in this context was presented by Scardi et al. $(2004,2005)$ in a recent study on Italian fish fauna, in which very reliable predictions about fish fauna composition were obtained on the basis of an ANN model on a regional scale. In particular, 20 environmental attributes (see Table 2.2.3) were used to predict the presence or absence of 32 fish species in North-Eastern Italian streams and rivers.

The ANN model was then able to correctly predict presence or absence of fish species in the majority of the cases included in an independent data set, which was only used for testing purposes. The percentage of Correctly Classified Instances (CCIs), i.e. the percentage of correct predictions about species presence or absence, ranged from 79 to $99 \%$, with $91.6 \%$ as the average value for the whole fish assemblage. Evaluating a species distribution model on the basis of CCIs, however, may be misleading, because very rare and very frequent species tend to be correctly

Table 2.2.3 Environmental attributes used as predictive variables by an Artificial Neural Network model for predicting fish assemblage composition (adapted from Scardi et al., 2004, 2005)

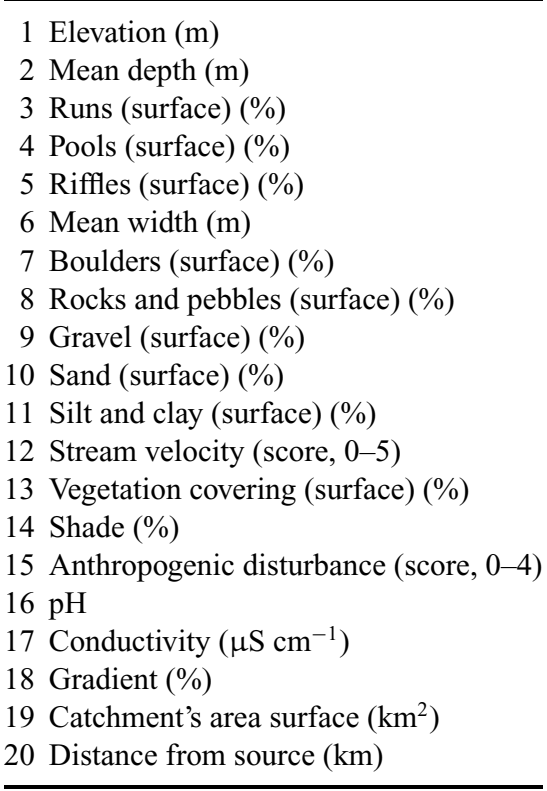


predicted in most cases, even by models that return constant outputs. It is obvious, for instance, that a species that occurs in 5 out of 100 records will be predicted with a $95 \%$ CCI accuracy by a model that always returns an 'absence' prediction. Therefore, a more accurate assessment of the ANN model performance was based on alternate validation strategies, including both K statistics (Cohen, 1960) and the Mantel test (Mantel, 1967). In the first case, model predictions were significantly different from those of a random model for 27 out of 32 species and the model only failed with very rare species ( $\leq 3 \%$ occurrence), i.e. when not enough information was available in data for describing species ecological properties and therefore for training (i.e., in ANN jargon, for calibrating) a model. In the second case, two Rogers and Tanimoto similarity matrices (Rogers and Tanimoto, 1960) were computed between 67 sites, based, respectively, on observed and predicted species composition. The resulting standardized Mantel statistics, which is a measure of the overall correlation between the two matrices, was highly significant $\left(R=0.84, p=1.0,10^{5}\right.$ permutations). This result provided a very clear evidence for the ability of the ANN model to consistently reproduce fish assemblage composition over a broad range of environmental conditions.

Further developments of ANN modeling of fish assemblage composition include quantitative predictions (species abundance or biomass) and, at least in the case of the most abundant species, predictions about the population structure (ranging from presence or absence of juveniles to frequency of age classes). It is very important to stress the fact that the feasibility of these advances in fish assemblage modeling depends only on the amount of available field data, as no methodological issues hinder such developments.

The need for large data bases as prerequisite for modeling is obvious, but it can be less strict in practice than in theory. In fact, modeling presence or absence of 32 fish species, as in the case that was just presented, implies $2^{32}$ (i.e. about 4 billion) different assemblage compositions. In practice, however, the number of combinations that really occur is much smaller because of the effects of biotic constraints and interactions (e.g. about a hundred in the North-Eastern Italian fish fauna). Therefore, the number of records that are needed to calibrate complex models (and ANNs in particular) is not as large as expected on a theoretical basis and practical applications are actually feasible.

Fish assemblage composition models are obviously very useful tools for monitoring activities. In fact, the evaluation of environmental quality may be directly based on the comparison between observed and modeled fish assemblage composition, using an appropriate similarity or distance coefficient for defining the deviation from the expected structure of the assemblage. The selection of an appropriate coefficient is not a trivial task, of course, and it must be carefully based on the characteristics and limits of both the model and the field data to be analysed. For instance, in large rivers the absence of a species may be due to sampling problems rather than to unfavourable environmental conditions, whereas many models systematically fail in predicting the presence of rare species. In all such cases, an asymmetrical coefficient (e.g. Jaccard's similarity) is certainly more appropriate than a symmetrical one 
(e.g. the Rogers and Tanimoto similarity), as the latter relies on the assumption that information about fish assemblage composition is complete. Moreover, there are differences among similarity coefficients (both symmetrical and asymmetrical) which depend on the relative weight that is assigned to concordances and discordances in species composition. Selecting different coefficients implies changes in 'contrast' (using a pictorial analogy) between 'lights' and 'shades' in the environmental quality picture. Obviously, it is up to the modeler to select the optimal 'contrast' settings, i.e. the best suited similarity or distance coefficient.

Another key issue in applying species distribution models to environmental quality assessment is the selection of an appropriate data set for model calibration (i.e. training, in the case of ANNs) and validation. In fact, it is obvious that a model aimed at predicting undisturbed community structure as a reference for environmental quality assessment should be only based on information about pristine sites. However, given the more or less severe environmental alterations that affect many regions, records from really pristine sites may be very difficult to find, even taking into account a whole ecoregion and both contemporary and historical data. In such cases, a different strategy should be considered, which includes in calibration and validation data sets not only pristine sites, but a broader range of environmental conditions. The predicted fish assemblage, in this case, cannot be regarded as an absolute reference, as it reflects the average conditions within a heterogeneous set of records. Nevertheless, predictions about the fish assemblage structure in hypothetical pristine conditions can still be obtained from simulations performed by properly 'tuning' the model inputs.

Finally, predicting fish assemblage structure is not only relevant to the definition of reference conditions aimed at the assessment of environmental quality (Olden and Jackson, 2002). In fact, it is an important achievement in the light of conservation and management strategies, and it can also help in optimizing sampling design for further research (Jackson and Harvey, 1997). Other applications include prediction and evaluation of habitat alteration due to changes in land use (Oberdorff et al., 2001), assessment of the potential risk of invasion and spread of exotic species (Peterson and Vieglais, 2001), optimization of strategies for species reintroduction (Evans and Oliver, 1995) and simulation of changes in fish assemblage induced by environmental restoration (Scardi et al., 2004, 2005).

\subsubsection{CONCLUSIONS AND PERSPECTIVES}

The assessment of ecological integrity based on biotic indices is becoming a standard practice, and fish-based methods certainly play a major role in this field. Their main advantages over methods based on other organisms are two. The first one is the minimal taxonomical knowledge that is needed to support a fish-based study. In fact, the number of fish species is always much smaller than that of other types of aquatic organisms, such as, for instance, benthic macroinvertebrates or benthic diatoms, while the average size of specimens is much larger, so that it is easy to 
identify species at a glance. The second advantage is related to the public awareness of the ecological role of fish fauna, which is also associated with a clear understanding of its social and economical value. In fact, while other organisms are only relevant in technical or scientific contexts, the role of fish fauna is well known and broadly accepted, even from people who do not have such background.

Model-based methods are rapidly emerging, as they are the only tools that allow us to bridge the gap between a limited amount of field data and an increasing demand for ecological assessment based on comparisons with reference conditions. In some cases, models may also play a role in reconstructing pristine assemblage structures that have disappeared as a consequence of diffuse anthropic disturbance. Although statistical models provided very good results in predicting fish species distribution on the basis of environmental variables (e.g. Oberdorff et al., 2001), Machine Learning techniques and, in particular, Artificial Neural Networks usually outperform conventional models (Olden and Jackson, 2002).

In the future, when more and more field data will become available, the role of biotic indices will probably become less important, as well as that of model-based assessment methods, while real data and real time series will be eventually used to set reference conditions for further evaluations.

However, model-based evaluation procedures will still play a major role in river reaches that are deeply modified by anthropic impacts. It is obvious that in these cases no reference data about pristine conditions will ever be available. Therefore, the only way to assess ecological integrity will be based on the deviation from the expected fish assemblage, i.e. from the potential fish fauna that would be present if all of the anthropic disturbances were removed.

Independently of the assessment method, however, it is very important to bear in mind that no entirely objective procedures exist. Multimetric biotic indices may be subjective in the selection and in the scaling of metrics, but also comparing observed fish assemblages to reference ones is not as objective as it may seem. In fact, the deviation from reference conditions cannot be univocally defined, as it depends on the choice of a similarity or distance coefficient, which in turn is inherently subjective. As a general rule of thumb, the shorter the path from data to ecological assessment, then the better the method.

In this framework, it is certainly useful to stress the role played by sampling procedures, which is usually not critical in streams and small wadeable rivers, whereas it is a major one in larger rivers. In fact, an exhaustive census of the whole fish assemblage can only be obtained by means of proper electrofishing, which is very common in sampling activities focused on small rivers and streams, while it usually fails in larger rivers because of the physical complexity of the aquatic environment. In such cases, only a combination of sampling techniques (e.g. gill nets, fyke nets and seines) may provide reliable information about the fish assemblage structure, and only from a qualitative point of view, as abundance data and occurrence of rare species are often affected by severe errors. Moreover, reliable quantitative data can be obtained only for abundant species, provided that sampling activities are not occasional and that fishing gear is properly standardized and operated. 
Finally, a caveat is needed about multimetric indices, biomarkers and other approaches not involving data and methods that closely and accurately represent the ecological complexity of aquatic ecosystems. These tools may play a role and are certainly useful in many cases, especially when specific disturbances are to be monitored. However, our ability to understand complex ecological processes relies on the amount of field data we collect and on the work of skilled ecologists, who are able to identify species, analyse relevant information, model biotic and abiotic relationships, and understand relevant results. Therefore, oversimplifying the interpretation of ecological data or inferring complex ecological properties on the basis of simple chemical analyses, although sometimes attractive from the point of view of water policy and management, is not a strategy that is likely to pay off in the long run. On the contrary, the growing demand for assessment of ecological integrity, e.g. according to the EU Water Framework Directive (European Union, 2000), must be regarded as a unique opportunity for raising a new generation of 'real' aquatic ecologists.

\section{REFERENCES}

Aguilar Ibarra, A., Gevrey, M., Park, Y. -S., Lim, P. and Lek S., 2003. 'Modelling the factors that influence fish guilds composition using a back-propagation network: assessment of metrics for indices of biotic integrity'. Ecol. Model., 160, 281-290.

An, K. -G., Park, S. -S. and Shin, J. -Y., 2002. 'An evaluation of a river health using the index of biological integrity along with relations to chemical and habitat conditions'. Environ. Int., 28, 411-420.

Badino, G., Forneris, G., Lodi E. and Ostracoli, G., 1992. 'Ichthyological Index, a new standard method for the river biological water quality assessment'. In: River Water Quality. Ecological Assessment and Control. Commission of the European Communities: Brussels, Belgium, pp. 729-730.

Baran, P., Lek, S., Delacoste, M. and Belaud, A., 1996. 'Stochastic models that predict trout population density or biomass on a mesohabitat scale'. Hydrobiologia, 337, 1-9.

Boet, P. and Fuhs, T., 2000. 'Predicting presence of fish species in the Seine River basin using artificial neuronal networks'. In: Artificial Neuronal Networks: Application to Ecology and Evolution, Environmental Science, Lek, S. and Gueguan, J.-F. (Eds). Springer-Verlag: Berlin, Germany, pp. 187-201.

Bramblett, R. G. and Fausch, K. D., 1991. 'Variable fish communities and the index of biotic integrity in a Western Great Plains river'. Trans. Am. Fish. Soc., 120, 752-769.

Bray, R. J. and Curtis, J. T., 1957. 'An ordination of the upland forest communities of southern Wisconsin'. Ecol. Monogr., 27, 325-349.

Cohen, J., 1960. 'A coefficient of agreement of nominal scales'. Edu. Psychol. Measurement, 20, $37-46$.

Connell, J. H., 1978. 'Diversity in tropical rainforests and coral reefs'. Science, 199, 1302-1310.

European Commission, 1992. Council Directive 92/43/ECC of 21st May 1992 on the Conservation of Natural Habitats and of Wild Fauna and Flora, Official Journal, L206. European Commission: Brussels, Belgium.

European Union, 2000. Parliament and Council Directive 2000/60/EC of 23rd October 2000. Establishing a Framework for Community Action in the Field of Water Policy. Official Journal, PE-CONS 3639/1/00 REV 1. European Union: Brussels, Belgium. 
Evans, D. O. and Oliver, C. H. 1995. 'Introduction of lake trout to inland lakes of Ontario, Canada: Factors contributing to successful colonization'. J. Great Lakes Res., 21 (Suppl. 1), 30-53.

Faush, K. D., Hawkes, C. L. and Parsons, M. G., 1988. Models that Predict the Standing Crop of Stream Fish from Habitat Variables: 1950-1985, General Technical Report PNW-GTR-213. US Department of Agriculture, Forest Service, Pacific North Reaserch Station: Portland, OR, USA.

Fausch, K. D., Lyons, J., Karr, J. R. and Angermeier, P. L., 1990. 'Fish communities as indicators of environmental degradation'. Am. Fish. Soc. Symp., 8, 123-144.

Fielding, A. H., 1999. 'An introduction to machine learning methods'. In: Machine Learning Methods for Ecological Applications, Fielding, A. H. (Ed.). Kluwer Academic Publishers: Boston, MA, USA, pp. 1-35.

Guegan, J. -F., Lek, S. and Oberdorff, T., 1998. 'Energy availability and habitat heterogeneity predict global riverine fish diversity'. Nature, 391, 382-384.

Harris, J. H., 1995. 'The use of fish in ecological assessments'. Aus. J. Ecol., 20, 65-80.

Hay, C. J., Van Zyl, B. J. and Steyn, G. J., 1996. 'A quantitative assessment of the biotic integrity of the Okavango River, Namibia, based on fish'. Water SA, 22, 263-284.

Hughes, R. M. and Oberdorff, T., 1999. 'Application of IBI concepts and metrics to waters outside the United States and Canada'. In: Assessing the Sustainability and Biological Integrity of Water Resources using Fish Communities, Simon, T. P. (Ed.). CRC Press: Boca Raton, FL, USA, pp. 79-93.

Hughes, R. M., Kaufmann, P. R., Herlihy, A. T., Kincaid, T. M., Reynolds, L. and Larsen, D. P., 1998. 'A process for developing and evaluating indices of fish assemblage integrity'. Can. J. Fish. Aquat. Sci., 55, 1618-1631.

Hugueny, B., Camara, S., Samoura, B. and Magassouba, M., 1996. 'Applying an index of biotic integrity based on fish assemblages in a West African river'. Hydrobiologia, 331, 71-78.

Jaccard, P., 1900. 'Contribution au problème de l'immigration post-glaciaire de la flore alpine'. Bull. Soc. Vaudoise Sci. Nat., 36, 87-130.

Jaccard, P., 1901. 'Etude comparative de la distribution florale dans une portion des Alpes et du Jura'. Bull. Soc. Vaudoise Sci. Nat., 37, 547-579.

Jaccard, P., 1908. 'Nouvelles recherches sur la distribution florale'. Bull. Soc. Vaudoise Sci. Nat., 44, 223-270.

Jackson, D. A. and Harvey, H. H., 1997. 'Qualitative and quantitative sampling of lake fish communities'. Can. J. Fish. Aquat. Sci., 54, 2807-2813.

Joy, M. K. and Death, R. G., 2005. 'Modelling of freshwater fish and macrocrustacean assemblages for biological assessment in New Zealand'. In: Modelling Community Structure in Freshwater Ecosystems, Lek, S., Scardi, M., Verdonschot, P. F. M., Descy, J. -P. and Park, Y. -S. (Eds). Springer-Verlag: Berlin, Germany, pp. 76-89.

Kamdem Toham, A. and Teugels, G. G., 1999. 'First data on an Index of Biotic Integrity (IBI) based on fish assemblages for the assessment of the impact of deforestation in a tropical West African river system'. Hydrobiologia, 397, 29-38.

Karr, J. R., 1981. 'Assessment of biotic integrity using fish communities'. Fisheries, 6, 21-27.

Karr, J. R. and Chu, E. W., 1997. Biological Monitoring and Assessment: Using Multimetric Indexes Effectively, EPA 235-R97-0001. US Environmental Protection Agency: University of Washington, Seattle, WA, USA.

Karr, J. R. and Dudley, D. R., 1981. 'Ecological perspective on water quality goals'. Environ. Management., 5, 55-68.

Karr, J. R., Fausch, F. D., Angermeier, P. L., Yant, P. R. and Schlosser, I. J., 1986. Assessing Biological Integrity in Running Waters: A Method and Its Rationale, Special Publication 5. Illinois Natural History Survey: Chicago, IL, USA. 
Kestemont, P., Didier, J., Depiereux, E. and Micha, J. C., 2000. 'Selecting ichtyological metrics to assess river basin ecological quality'. Arch. Hydrobiol., 121, 321-348.

Kleynhans, C. J., 1999. 'The development of a fish index to assess the biological integrity of South African rivers'. Water $S A, \mathbf{2 5}, 265-278$.

Kurtz, J. A., Jackson L. E. and Fisher, W. S., 2001. 'Strategies for evaluating indicators based on guidelines from the Environmental Protection Agency's Office of Research and Development'. Ecol. Indicators, 1, 49-60.

Lance, G. N. and Williams, W. T., 1966. 'Computer programs for classification'. In: Proceedings of the ANCCAC Conference, May, 1966, Canberra, Australia, Paper 12/3.

Legendre, P. and Legendre, L., 1998. Numerical Ecology, 2nd Edition (in English). Elsevier Amsterdam, The Netherlands.

Lek, S. and Guégan, J. F., 1999. 'Artificial neural networks as a tool in ecological modelling, an introduction'. Ecol. Modelling, 120, 65-73.

Lek, S., Belaud, A., Baran, P., Dimopoulos, I. and Delacoste, M., 1996a. 'Role of some environmental variables in trout abundance models using neural networks'. Aquat. Living Res., 9, 23-29.

Lek, S., Delacoste, M., Baran, P., Dimopoulos, I., Lauga, J. and Aulagnier, S., 1996b. ‘Application of neural networks to modelling nonlinear relationships in ecology'. Ecol. Modelling, 90, 39-52.

Lyons, J., Navarro-Pérez, S., Cochran, P. A., Santana, E. and Guzmán-Arroyo, M., 1995. 'Index of biotic integrity based on fish assemblages for the conservation of streams and rivers in West-Central Mexico'. Conserv. Biol., 9, 569-584.

Mantel, N., 1967. 'The detection of desease clustering and a generalized regression approach'. Cancer Res., 27, 209-220.

Mastrorillo, S., Lek, S. and Dauba, F., 1997a. 'Predicting the abundance of minnow Phoxinus phoxinus (Cyprinidae) in the River Ariege (France) using artificial neural networks'. Aquat. Living Res., 10, 169-176.

Mastrorillo, S., Lek, S., Dauba, F., and Belaud, A., 1997b. 'The use of artificial neural networks to predict the presence of small-bodied fish in a river'. Freshwater Biol., 38, 237-246.

Oberdorff, T. and Hughes, R. M., 1992. 'Modification of an index of biotic integrity based on fish assemblages to characterize rivers of the Seine Basin, France'. Hydrobioly, 228, 117-130.

Oberdorff, T., Pont, D., Hugueny, B. and Chessel, D., 2001. 'A probabilistic model characterizing fish assemblages of French rivers: a framework for environmental assessment'. Freshwater Biol., 46, 399-415.

Olden, J. D. and Jackson, D. A., 2001. 'Fish-habitat relationships in lakes: gaining predictive and explanatory insight by using artificial neural networks'. Trans. North Am. Fish. Soc., 130, 878-897.

Olden, J. D. and Jackson, D. A., 2002. 'A comparison of statistical approaches for modelling fish species distributions'. Freshwater Biol., 47, 1976-1995.

Peterson, A. T. and Vieglais, D. A., 2001. 'Predicting species invasions using ecological niche modeling: new approaches from bioinformatics attack a pressing problem'. Bioscience, 51, 363-371.

Plafkin, L. P., Barbour, M. T., Porter, K. D., Gross, S. K. and Hughes, R. M., 1989. Rapid Bioassessment Protocols for Use in Streams and Rivers: Benthic Macroinvertebrates and Fish. US Environmental Protection Agency: Washington, DC, USA.

Ramm, A. E., 1988. 'The community degradation index: A new method for assessing the deterioration of aquatic habitats'. Water Res., 22: 293-301.

Rogers, D. J. and Tanimoto, T. T., 1960. 'A computer program for classifying plants'. Science, 132, $1115-1118$. 
Scardi, M., Cataudella, S., Ciccotti, E., Di Dato, P., Maio, G., Marconato, E., Salviati, S., Tancioni, L., Turin, P. and Zanetti, M., 2004. 'Previsione della composizione della fauna ittica mediante reti neurali artificiali'. Biol. Ambient., 18, 1-8.

Scardi, M., Cataudella, S., Ciccotti, E., Di Dato, P., Maio, G., Marconato, E., Salviati, S., Tancioni, L., Turin, P. and Zanetti, M., 2005. 'Optimisation of artificial neural networks for predicting fish assemblages in rivers'. In: Modelling Community Structure in Freshwater Ecosystems, Lek, S., Scardi, M., Verdonschot, P. F. M., Descy, J. -P. and Park, Y. -S. (Eds). Springer-Verlag: Berlin, Germany, pp. 114-129.

Schmutz, S., Kaufmann, M., Vogel, B., Jungwirth, M. and S. Muhar, 2000. 'A multi-level concept for fish-based, river-type-specific assessment of ecological integrity'. Hydrobiologia, 422/423, 279-289.

Shamsudin, P., 1988. 'Water quality and mass fish mortality at Mengabang lagoon, Trengganu, Malaysia'. Malay. Nat. J., 41, 515-527.

Simon, T. P. and Lyons, J., 1995. 'Application of the index of biotic integrity to evaluate water resource integrity in freshwater ecosystems'. In: Biological Assessment and Criteria: Tools for Water Resource Planning and Decision Making, Davis, W. S. and Simon, T. P. (Eds). Lewis Publishers: Boca Raton, FL, USA, pp. 245-262.

Steedman, R. J., 1988. 'Modification and assessment of an index of biotic integrity to quantify stream quality in southern Ontario'. Can. J. Fish. Aquat. Sci., 45, 492-501.

Suter, G. W., 1993. 'A critique of ecosystem health concepts and indexes'. Environ. Toxicol. Chem., 12, 1533-1539.

van der Oost, R., Beyer, J. and Vermeulen, N. P. E., 2003. 'Fish bioaccumulation and biomarkers in environmental risk assessment: a review'. Environ. Toxicol. Pharmacol., 13, 57-149.

Whitfield, A. K., 1996. 'Fishes and the environmental status of South African estuaries'. Fish. Management Ecol., 3, 45-57.

Whittaker, R. H., 1952. 'A study of summer foliage insect communities in the Great Smoky Mountains. Ecol. Monogr., 22, 1-44.

Wright, J. F., Armitage, P. D. and Furse, M. T., 1989. 'Prediction of invertebrate communities using stream measurements'. Regulated Rivers Res. Management, 4, 147-155. 
